\title{
Acute influence of cigarette smoke on secretion of pulmonary surfactant in rat alveolar type II cells in culture
}

\author{
H.R.W. Wirtz, M. Schmidt
}

Acute influence of cigarette smoke on secretion of pulmonary surfactant in rat alveolar type II cells in culture. H.R.W. Wirtz, M. Schmidt. CERS Journals Ltd 1996.

ABSTRACT: It has been shown, that smoking results in a lower yield of surfactant associated phospholipids in bronchoalveolar lavage (BAL). Indirect evidence suggests impaired secretion. In the present study, we investigated the influence of cigarette smoke on surfactant secretion in cultured rat alveolar type II cells.

Smoke exposure was achieved by bubbling the smoke of four cigarettes through Dulbecco's modified Eagle's medium (DMEM) which was adjusted to a reference absorption value of 1.36 at $320 \mathrm{~nm}$. Cells were preincubated with various dilutions of cigarette smoke-treated medium for $30 \mathrm{~min}$, and were then exposed to this medium for $2 \mathrm{~h}$. After this time, secretion of $\mathbf{3} \mathrm{H}$-choline-labelled phosphatidylcholine (PC) was measured as a marker of surfactant secretion.

A 10 fold dilution of cigarette smoke-treated medium inhibited PC secretion stimulated by a combination of terbutaline, adenosine triphosphate and 12-O-tetradecanoylphorbol-13-acetate by over 50\%, but did not alter basal secretion. Exposure to less concentrated cigarette smoke-treated medium resulted in less inhibition. Cellular injury was not observed with the concentrations of cigarette smoke-treated medium used in this study. The gas phase of cigarette smoke was not inhibitory at comparable concentrations. Longer exposure to cigarette smoke-treated medium resulted in increased inhibition of $\mathrm{PC}$ secretion. The cigarette smoke ingredients, nicotine and benzo[a]pyrene, failed to inhibit PC secretion. Secretion of type II cells exposed to cigarette smoke-treated medium at lower temperatures was not affected. Addition of antioxidants to medium and cells during the preincubation and secretion period did not alter cigarette smoke-treated medium-induced inhibition of stimulated PC secretion.

These results demonstrate a direct inhibitory effect of cigarette smoke constituents on surfactant secretion in type II cells. Inhibition is mediated by compounds contained predominantly in the particulate phase of cigarette smoke. Inactivation of the inhibitory effect by lower temperatures suggests involvement of processes such as enzymatic bioactivation or active transport mechanisms.

Eur Respir J., 1996, 9, 24-32.
Dept of Medicine, University of Würzburg, Würzburg, Germany.

Correspondence: H.R.W. Wirtz

Medizinische Klinik

Universität Würzburg

Josef Schneider Str. 2

97080 Würzburg

Germany

Keywords: Antioxidants

cigarette smoke

surfactant secretion

type II cells

Received: September 121994

Accepted after revision October 71995

This work was supported in part by a grant from Forschungsgesellschaft Rauchen und Gesundheit MBH, Germany.
Evidence that the yield of surfactant-associated phospholipids in bronchoalveolar lavage fluid of young smokers is reduced compared to healthy controls dates back more than 20 yrs [1], and has recently been confirmed $[2,3]$. However, the influence of cigarette smoking on the surfactant system has not been well established. Cessation of smoking resulted in a return of the amount of phospholipids to normal levels within 2 weeks [1]. It has been suggested, that structural changes in the lungs of smokers might be responsible for the observed reduction in phospholipid yield [4], but it seems unlikely that these changes would reverse within a short period. Animal experiments resulted in similar findings. Synthesis does not appear to be affected, as the incorporation rate of labelled palmitic acid into surfactant phospholipids in dogs was not altered following exposure to cigarette smoke [5]. In addition, the number of alveolar type II cells tends to be larger in smokers than in nonsmokers [6]. Finally, the amount of total surfactant-associated phospholipids in the lungs of smokers is not diminished, in contrast to the amount of extracellular surfactant, which suggests a disturbance somewhere during the process of secretion [4].

The aim of this study was to investigate the acute effects of cigarette smoke on secretion of surfactant. An in vitro cell culture model was chosen, in order to eliminate the influence of known effects of cigarette smoke on, for instance, inflammatory cells, and because it facilitated investigation of the mechanisms. Cell culture medium was treated with cigarette smoke and cells were exposed to this medium before or during secretion stimulated by means of agonists. In this study, inhibition of stimulated secretion of phosphatidylcholine, a marker of pulmonary surfactant, was observed in cultured rat 
alveolar type II cells. The extent of inhibition depended on the dose of smoke constituents in the medium and on the time that cells were exposed to it. The role of oxidants and the influence of a reduced metabolic rate induced by low temperature were also investigated.

\section{Materials and methods}

Dulbecco's modified Eagle's medium (DMEM) was purchased from Gibco (Eggenstein, Germany). L-glutamine, penicillin, gentamicin, rat immunoglobulin $\mathrm{G}$ (IgG), deoxyribonuclease (DNase) I, trypsin, ethylene glycol tetra-acetic acid (EGTA), adenosine triphosphate (ATP), terbutaline, 12-O-tetradecanoylphorbol-13-acetate (TPA), (-)-nicotine (two forms: nicotine free base, FW 162.2; and (-)-nicotine hemisulphate salt, FW 211.3), benzo[a]pyrene, glutathione, superoxide dismutase (SOD) and catalase (CAT) were from Sigma (Deisenhofen, Germany). Deferoxamine mesylate was a gift from Ciba Geigy (Wehr, Switzerland). Porcine elastase was from Elastin Products Co. (Owensville, USA). 1R1 reference cigarettes and Cambridge Filters were purchased from the Tobacco \& Health Research Institute at the University of Kentucky (Lexington, USA). ${ }^{3} \mathrm{H}$-labelled choline and ${ }^{3} \mathrm{H}$-labelled adenosine were from Amersham Buchler (Braunschweig, Germany).

\section{Preparation of cigarette smoke-treated medium}

Smoke generated by the combustion of four 1R1 cigarettes was bubbled through $100 \mathrm{~mL}$ of DMEM in a conical $250 \mathrm{~mL}$ culture flask. Suction was regulated, so that sidestream smoke developed during the entire combustion, lasting $3 \mathrm{~min}$ for each cigarette. Absorbance of cigarette smoke-treated medium (CSTM) was measured at $320 \mathrm{~nm}$ (see below). CSTM was then diluted 10, 25, 50,75 or 100 fold with fresh DMEM. A 10 fold dilution will be indicated in graphs as 1:10. To standardize the concentration of CSTM, dilution was adjusted as described below. Finally, CSTM was incubated for 90 $\min$ at $37^{\circ} \mathrm{C}$, in room air with $10 \% \mathrm{CO}_{2}$. The $\mathrm{pH}$ of CSTM was not different from that of untreated DMEM.

\section{Standardization of CSTM}

Preliminary experiments showed maximal absorption of cigarette smoke treated DMEM (with phenol red) at $320 \mathrm{~nm}$, when regular DMEM was used as a blank and set to zero. The smoke of four 1R1 cigarettes in these experiments resulted in an absorbance of 1.36. This value was used as a reference for the preparation of CSTM throughout this study. When CSTM was diluted with fresh DMEM, a linear relationship between the extent of dilution and absorption was seen $(y=0.0015+$ $1.38 \mathrm{x} ; \mathrm{R}=0.999)$. Taking advantage of the linearity of this relationship, subsequent CSTM preparations were standardized by dividing actual extinction (mean for all experiments: $1.41 \pm 0.34$ ) by the reference value 1.36 . The resulting standardization factor was then multiplied by $10,25,50,75$ or 100 to give the final factor of dilution.

Preparation of gas phase cigarette smoke-treated medium

For experiments examining the influence of the particle-free phase of cigarette smoke on surfactant secretion, a Cambridge Filter (Tobacco \& Health Research Institute, University of Kentucky, USA) was used to filter cigarette smoke, which removes $99.9 \%$ of the particulate phase [7]. For each cigarette, a new filter was used. The resulting medium was termed gas phase cigarette smoketreated medium (gpCSTM). Because gpCSTM did not show much absorption at $320 \mathrm{~nm}$, standardization was not performed in these experiments and gpCSTM was directly diluted $10,25,50,75$ or 100 fold as indicated in the experiment.

\section{Isolation of alveolar type II cells}

Alveolar type II cells were isolated from male, adolescent Sprague Dawley rats by elastase digestion, and differential adherence on IgG-coated Petri dishes as described previously $[8,9]$. Type II cells were $88+6.8 \%$ pure at the time of plating, judged by modified Papanicolaou staining [10]. Cells were plated at a density of $7.5 \times$ $10^{5}$ cells $35 \mathrm{~mm}$ dish $^{-1}$ and were cultured in DMEM with $10 \%$ foetal calf serum (FCS), penicillin $\left(100 \mathrm{U} \cdot \mathrm{mL}^{-1}\right)$, gentamicin $\left(50 \mu \mathrm{g} \cdot \mathrm{mL}^{-1}\right)$ and L-glutamine $(2 \mathrm{mM})$ at $37^{\circ} \mathrm{C}$, in room air with $10 \% \mathrm{CO}_{2}$. Cells were labelled with ${ }^{3} \mathrm{H}$-choline $\left(1 \mu \mathrm{Ci} \cdot \mathrm{mL}^{-1} \mathrm{DMEM}\right)$ for $22 \mathrm{~h}$. After this time, adherent cells were washed four times with DMEM.

\section{Secretion assay}

PC secretion was measured by labelling cells with ${ }^{3} \mathrm{H}-$ choline as indicated, removing excess label in the supernatant by washing, stimulating secretion with agonists, harvesting the supernatant including secreted material and measuring radioactivity in the lipophilic phase by scintillation counting (i.e. cell-synthesized ${ }^{3} \mathrm{H}-$ phosphatidylcholine) following lipid extraction [11]. Cells were harvested by scraping in ethanol and processed as described for supernatant. Secretion (i.e. counts in the supernatant) was then expressed in percentage of total counts (cells and supernatant). A mixture of $10^{-4} \mathrm{M}$ terbutaline, $10^{-8} \mathrm{M}$ TPA, and $10^{-4} \mathrm{M}$ ATP was used in all experiments to stimulate surfactant secretion, with the exception of those experiments examining the influence of CSTM on secretion stimulated by single agonists of equal concentrations. The combination of terbutaline, TPA and ATP in the concentrations indicated above resulted in strong stimulation of surfactant secretion in alveolar type II cells and will be referred to as T/T/A. Agonists were added to increase the volume by $2.5 \%$. Control cells received equivalent volumes of normal saline. Secretion was allowed for $2 \mathrm{~h}$ in the incubator. 


\section{Experimental design}

The influence of CSTM or gpCSTM on stimulated secretion of PC in type II cells was examined by exposing cells to control medium or CSTM during a $2 \mathrm{~h}$ secretion period, that was stimulated by adding T/T/A agonists as described above. Because it has been shown that agonist-induced secretion is strongest shortly after addition of the agonists $[12,13]$, cells were preincubated with the experimental medium for another $30 \mathrm{~min}$ prior to the secretion period, so that any effect on cells was influential at the time of stimulation.

An alternative experimental design was used to investigate the influence of CSTM exposure-time on stimulated secretion (fig. 1): exposure to CSTM was performed $3 \mathrm{~h}$ prior to the secretion period for various exposure times (ETs) as indicated in figure 1b. Medium was then exchanged for DMEM for the remainder of the $3 \mathrm{~h}$ period. After that time, fresh medium and agonists were added, and the $2 \mathrm{~h}$ secretion period was started (preexposure model). This change in the experimental procedure was necessary to study various exposure time intervals without changing the period of secretion, which would also result in a change of the secretory response. Inhibition of stimulated secretion turned out to be very similar in experiments with CSTM exposure during secretion and experiments with CSTM exposure up to $3 \mathrm{~h}$ prior to secretion.

The pre-exposure model was also chosen to investigate the effect of CSTM exposure at low temperature on stimulated PC secretion, because low temperature during the secretion period inhibits secretion [12]. In low temperature experiments, cells on culture plates were slowly cooled to $4^{\circ} \mathrm{C}$ whilst resting on a perfused plate, which was hooked to a fluid thermostat. The bottom of the culture dish was immersed in $2 \mathrm{~mm}$ water to assure

$$
\text { a) }
$$

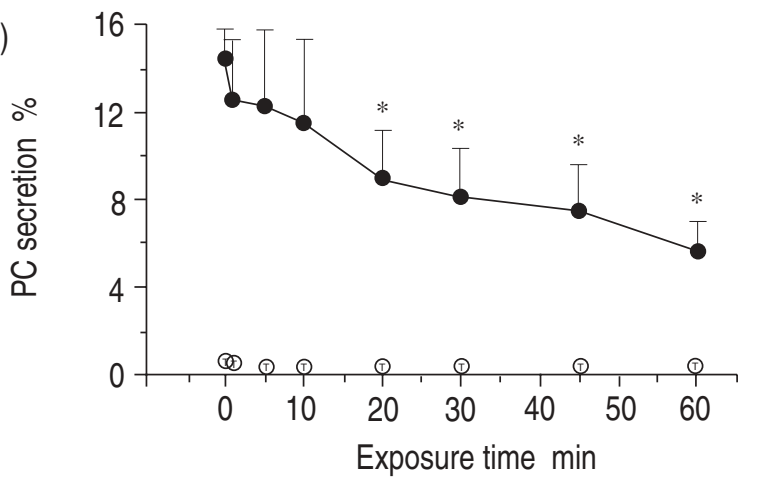

b)

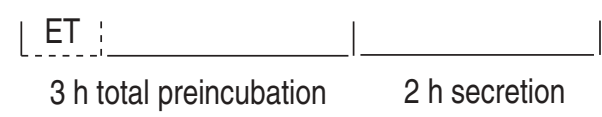

Fig. 1. - a) PC secretion $($ mean \pm SD) in type II cells, exposed to 1:10 CSTM $3 \mathrm{~h}$ prior to the secretion period for exposure times (ETs) between 0 and $60 \mathrm{~min}$, as indicated on the X-axis. $O$ : basal secetion; : $\mathrm{T} / \mathrm{T} / \mathrm{A}$ stimulated secretion $(\mathrm{n}=3)$. *:significant difference of stimulated conditions vs stimulated control (i.e. 0 min exposure time). PC: phosphatidylcholine; CSTM: cigarette smoke-treated medium; T/T/A: combination of terbutaline, 12-O-tetradecanoylphorbol-13-acetate(TPA) and adenosine triphosphate (ATP). b) indicates the experimental design. transduction of the temperature to the cell culture dish. $\mathrm{CO}_{2}$ was maintained at $10 \%$. Cells were exposed to $\mathrm{CSTM}$ at $4^{\circ} \mathrm{C}$ for $60 \mathrm{~min}$. The $60 \mathrm{~min}$ exposure time was chosen because it resulted in a greater than $50 \%$ reduction of stimulated secretion in exposure-time experiments (see below and fig. 1). Following CSTM exposure to low temperature, the medium was exchanged for untreated DMEM at $4^{\circ} \mathrm{C}$ and then warmed slowly to $37^{\circ} \mathrm{C}$ over $10 \mathrm{~min}$ followed by a $2 \mathrm{~h}$ secretion period $\left(37^{\circ} \mathrm{C}, 10 \% \mathrm{CO}_{2}\right.$ in room air, $\pm \mathrm{T} / \mathrm{T} / \mathrm{A}$ agonists $)$. Control cells were treated identically, but kept at $37^{\circ} \mathrm{C}$, basal as well as stimulated cells in DMEM at 4 and at $37^{\circ} \mathrm{C}$.

Experiments with antioxidants were performed in a similar manner to those in which cells were exposed to CSTM during the secretion period. However, to ensure that sufficient antioxidants were present in the cellular microenvironment at the time of contact with CSTM, antioxidants were added $3 \mathrm{~h}$ prior to exposure to CSTM. In addition, CSTM in this series of experiments was preincubated separately for $60 \mathrm{~min}$ with the chosen antioxidant, before it was used in the secretion assay. Thus, cells were incubated with CSTM containing antioxidants during the $30 \mathrm{~min}$ preincubation and during the secretion period.

Control cells were treated identically omitting antioxidants prior to secretion, during exposure to CSTM, during preincubation and during secretion. Basal and stimulated secretion was determined in control cells in DMEM with antioxidants present $3 \mathrm{~h}$ before the experiment, during preincubation and during the secretion period to control for stimulation or inhibition of surfactant secretion by these compounds.

\section{Control for cellular injury by CSTM}

Cellular integrity was investigated by several methods. 1) vital dye exclusion with erythrosin B $5 \%(\mathrm{w} / \mathrm{v})$ : preliminary experiments showed that undiluted CSTM resulted in erythrosin B uptake after $2.5 \mathrm{~h}$ in most cells, whilst viability in cells exposed to a five fold dilution was $94 \%$ for unstimulated cells and $65 \%$ for agonist stimulated cells. Further dilutions of undiluted, standardized CSTM, i.e. 10 through 100 fold diluted, did not result in increased erythrosin B uptake compared to cells exposed to DMEM and no difference existed between stimulated and unstimulated cells. 2) Lactic acid dehydrogenase (LDH) activity was measured in the supernatant as well as in the cellular fraction of all experimental culture dishes used in surfactant secretion assays, and release of LDH was expressed as percentage release of total LDH (i.e. supernatant and cellular fraction) in the supernatant. Release of $\mathrm{LDH}$ exceeding $1 \%$ of total $\mathrm{LDH}$ led to exclusion of the dish from evaluation. LDH was measured by a fluorimetric assay [14]. Less than $1 \%$ of all wells examined were excluded for that reason and no preference was observed for wells that had been exposed to CSTM. 3 ) In a separate series of experiments, ${ }^{3} \mathrm{H}$-adenine (specific activity $27 \mu \mathrm{Ci} \cdot \mathrm{mmol}^{-1}$ ) was used to label cells. Spontaneous release of counts into the culture medium and the maximal release of counts after cells were lysed 


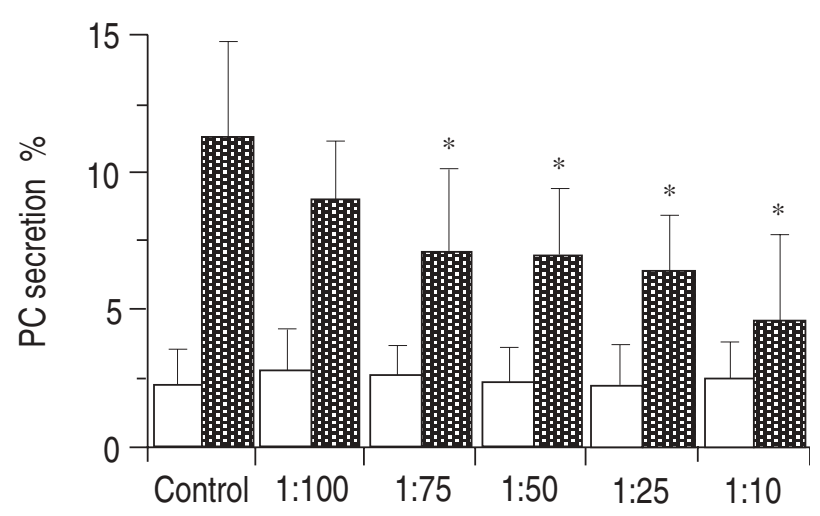

Fig. 2. - PC secretion (mean \pm SD) in type II cells exposed to dilutions of CSTM and to regular DMEM (i.e. controls). $\square$ : basal secretion; $\quad$ 明 : T/T/A/ stimulated secretion $(n=7)$. *: significant difference vs stimulated control (repeated ANOVA followed by Bonferroni post hoc test). DMEM: Dulbecco's modified Eagle's medium; ANOVA: analysis of variance. For further abbreviations see legend to figure 1 .

with concentrated $\mathrm{NaOH}$ was determined. A cytotoxicity index (CI) was calculated:

$$
\mathrm{CI}=(\mathrm{X}-\mathrm{C}) /(\mathrm{M}-\mathrm{C})
$$

where $\mathrm{X}=$ release on the plate evaluated; $\mathrm{C}=$ basal release on control plates; and $\mathrm{M}=$ maximal release following addition of $\mathrm{NaOH}$. This model has been used to evaluate toxicity of paraquat in alveolar type II cells in culture [15].

\section{Statistics}

Statistical calculations were made using the InStat ${ }^{\mathrm{TM}}$ software package (GraphPad software). All conditions were performed in duplicate or triplicate wells. All studies were repeated at least three times $(n=$ the number of separate cell isolations). Statistical analysis was performed by one way analysis of variance (ANOVA) with Student Newman Keuls post hoc analysis unless otherwise stated. Significance was assumed at the 5\% level. All numbers in the text and graphs show mean \pm SD.

\section{Results}

\section{Exposure to medium treated with whole smoke (CSTM)}

Basal secretion of phosphatidylcholine in alveolar type II cells was $2.1 \pm 1.3 \%$ in the $2 \mathrm{~h}$ secretion period. When

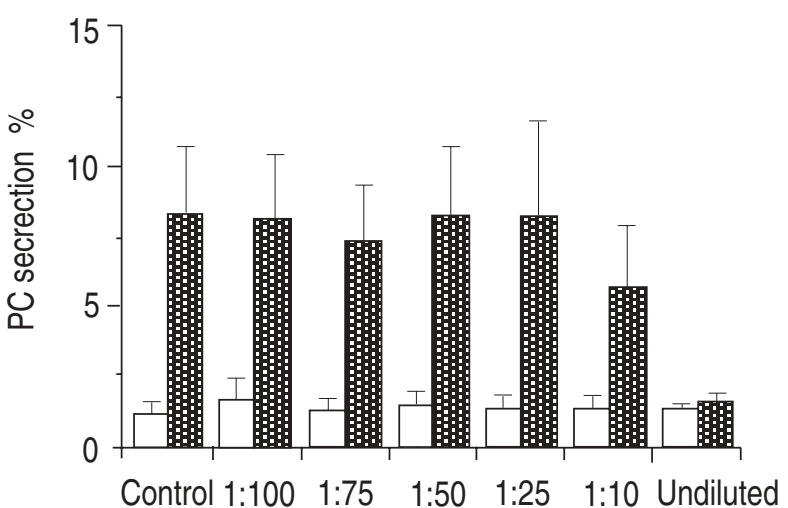

Fig. 3. - PC secretion (mean \pm SD) in type II cells exposed to various dilutions of gpCSTM and to regular DMEM (i.e controls). $\square$ : basal secretion; 明 : T/T/A stimulated secretion $(n=7)$. gpCSTM: gas phase cigarette smoke-treated medium; DMEM: Dulbecco's modified Eagle's medium. For further abbreviations see legend to figure 1 .

cells were stimulated with T/T/A secretagogues, a five fold or more increase was observed $(\mathrm{p}<0.01)$ (fig. 2). Basal secretion in cells exposed to $100,75,50,25$ and 10 fold dilutions of CSTM did not differ from basal secretion in control cells, suggesting that CSTM did not alter basal PC secretion. However, PC secretion stimulated by T/T/A was inhibited in a dose-dependent fashion in all but the 100 fold dilution of CSTM compared to stimulated control cells (fig. 2).

Because the three secretagogues used for stimulation of secretion are known to be mediated by different pathways of transmembrane signalling, experiments were conducted with each of the secretagogues separately and stimulated secretion in 10 fold diluted CSTM was compared to that in untreated DMEM. Stimulated secretion in CSTM was expressed as the percentage of the increase in secretion in stimulated cells in DMEM. No significant difference existed in the extent of inhibition between the three agonists (table 1).

Counts (counts per minute (cpm) after Folch extraction, i.e. incorporated into phospholipids) in the cellular fraction $(84,610 \pm 31,876)$ or in the cellular plus medium fraction $(89,502 \pm 33,826)$ of stimulated cells exposed to 10 fold diluted CSTM were not different from counts in the cellular fraction $(76,006 \pm 25,534)$ or the cellular plus medium fraction $(85,216 \pm 30,283)$ of stimulated control cells $(n=7 ; p>0.05)$. The larger difference between total counts and cellular fraction in control cells reflects increased secretion.

Table 1. - Secretory response of type II cells to secretagogues in DMEM and CSTM

\begin{tabular}{lcccccc}
\hline Condition & $\begin{array}{c}\text { Secretion } \\
\text { in DMEM } \\
\text { \% secreted }\end{array}$ & $\begin{array}{c}\text { Secretion in } \\
\text { CSTM } \\
\text { \% secreted }\end{array}$ & $\begin{array}{c}\text { Increase } \\
\text { in DMEM } \\
\text { \% of basal }\end{array}$ & $\begin{array}{c}\text { Increase } \\
\text { in CSTM } \\
\text { \% of basal }\end{array}$ & $\begin{array}{c}\text { Increase in CSTM } \\
\text { \% of increase } \\
\text { in DMEM }\end{array}$ & $\mathrm{n}$ \\
\hline Basal & $1.2 \pm 0.5$ & $1.3 \pm 0.3$ & - & - & - & 6 \\
T/T/A & $7.5 \pm 1.4$ & $4.1 \pm 1.1$ & $630 \pm 401$ & $229 \pm 76$ & 36.3 & 6 \\
ATP & $5.1 \pm 1.3$ & $2.6 \pm 0.7$ & $398 \pm 270$ & $115 \pm 59$ & 29.0 & 6 \\
Terbutaline & $2.0 \pm 0.4$ & $1.4 \pm 0.2$ & $82 \pm 66$ & $21 \pm 52$ & 25.2 & 6 \\
TPA & $5.2 \pm 1.4$ & $2.4 \pm 1.1$ & $413 \pm 312$ & $87 \pm 67$ & 20.9 & 6 \\
\hline
\end{tabular}

Values are presented as mean \pm SD. DMEM: Dulbecco's modified Eagle's medium; CSTM cigarette smoketreated medium; T/T/A: combination of terbutaline, TPA and ATP; TPA: 12-O-tetradecanoylphorbol-13acetate; ATP: adenosine triphosphate. 


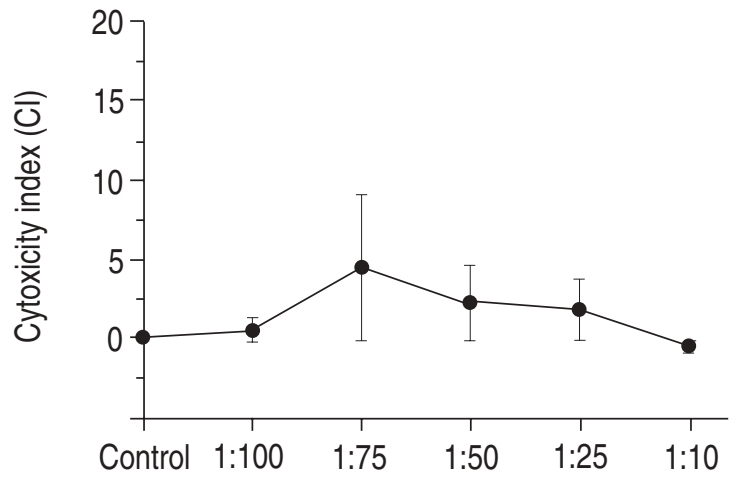

Fig. 4. - Cytotoxicity index (CI) (mean \pm SD) of type II cell cultures exposed to DMEM (control) or dilutions of CSTM $(n=4)$. Repeated ANOVA revealed no significant differences. For abbreviations see legend to fig. 3 .

\section{Cytotoxicity index}

There was no significant increase of CI when CSTM was applied in a 10 fold or higher dilution (fig. 4).

\section{Influence of exposure time on inhibition of secretion}

Type II cells were exposed to 10 fold diluted CSTM for exposure times (ETs) varying from 0 to $60 \mathrm{~min}$. As described under experimental design, ET constituted the first part of a $3 \mathrm{~h}$ preincubation, which was followed by the $2 \mathrm{~h}$ secretion period. Figure 1 shows that this type of varied time exposure prior to secretion resulted in a very similar maximal inhibition of stimulated secretion when compared to experiments in which cells were exposed to various CSTM concentrations during the secretion period itself (fig. 2). Longer ET led to greater reduction of stimulated secretion. An ET as low as 1 min decreased mean stimulated secretion by $11.3 \pm 9.8 \%$, although a significant inhibition was first observed after $20 \mathrm{~min}$ of exposure followed by $160 \mathrm{~min}$ in DMEM ( $3 \mathrm{~h}$ total). All ETs longer than that, resulted in increased inhibition (fig. 1).

\section{Exposure of cells to gas phase smoke (gpCSTM)}

Gas phase CSTM diluted 10-100 fold did not result in significant reduction of PC secretion stimulated by T/T/A in type II cells. Because no significant inhibition of stimulated secretion was observed at these dilutions, undiluted gpCSTM was also examined and resulted in a significant and almost complete inhibition of stimulated PC secretion (fig. 3). Using undiluted gpCSTM was possible because the toxicity of gpCSTM was considerably less compared to whole smoke.

\section{Antioxidants}

Antioxidants were used to examine the effects of reactive oxygen species (ROS) contained in CSTM, or developed during the incubation period of CSTM. Catalase and superoxide dismutase (SOD) are known scavengers of oxygen radicals. These compounds were added to experimental wells prior to and during secretion, and were also added to CSTM before it was used in the experiment. Catalase and SOD were, therefore, able to react with ROS present in the CSTM and ROS reaching the surface of the cells, but were not taken up by type II cells. Catalase and SOD were added in concentrations that were equivalent to or higher than those that had been used effectively in other cell culture models (see below). Catalase and SOD of the highest applied concentration were without effect on basal or stimulated secretion in control cells. Addition of these two antioxidants did not result in a change in CSTM-induced inhibition of stimulated surfactant secretion (fig. 5a).
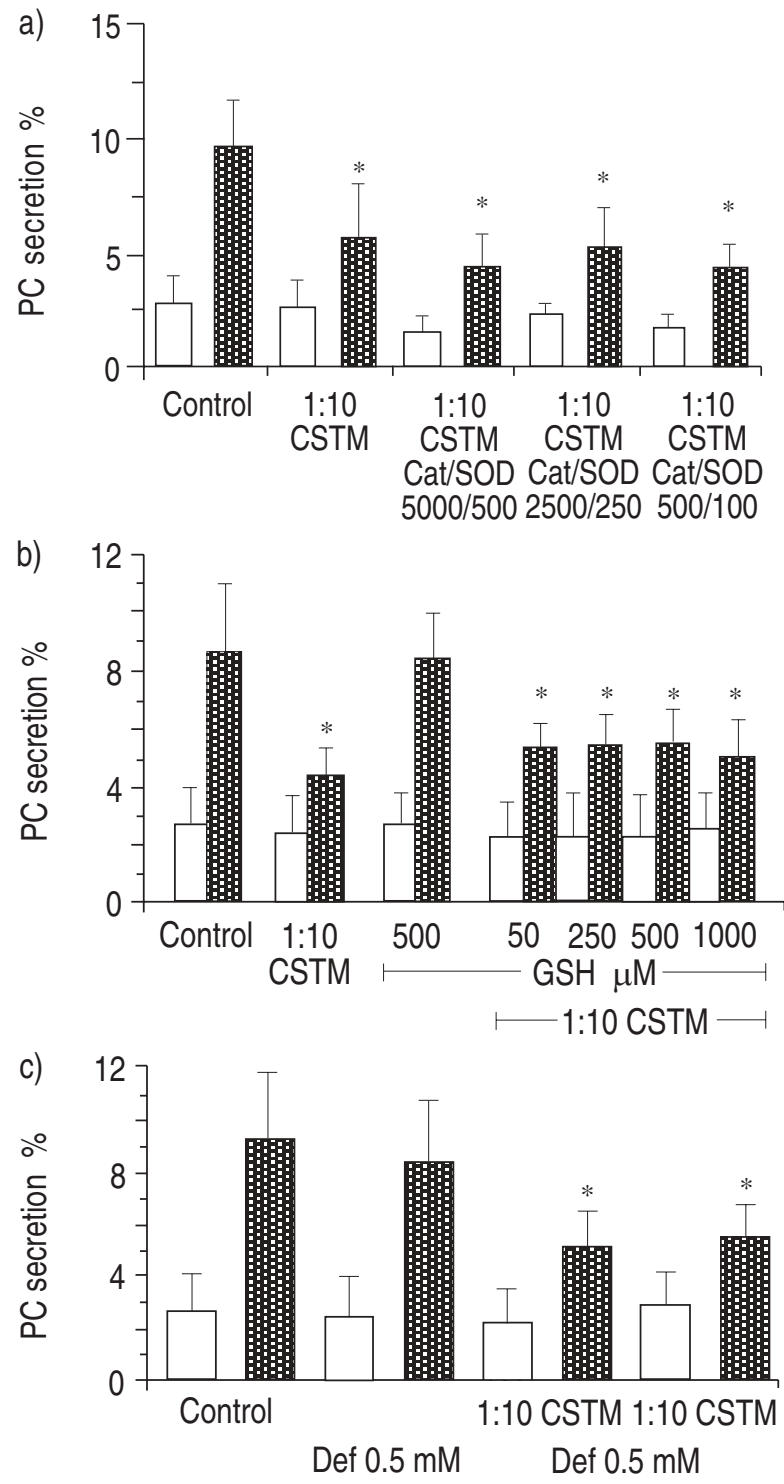

Fig. 5. - PC secretion (mean $\pm \mathrm{SD})$ in type II cells exposed to control medium and 1:10 CSTM. with or without different antioxidants. $\square$ : basal secretion; 眀 : T/T/A stimulated secretion. *: significant difference of stimulated conditions $v s$ stimulated control. a) catalase (Cat) and superoxide dismutase (SOD); numbers are $\mathrm{U} \cdot \mathrm{mL}^{-1}(\mathrm{n}=3$ for the two lower Cat/SOD concentrations and $n=7$ for all other columns). b) Glutathione (GSH); n=6. c) Deferoxamine (Def); n=4. For abbreviations see legend to figure 1 


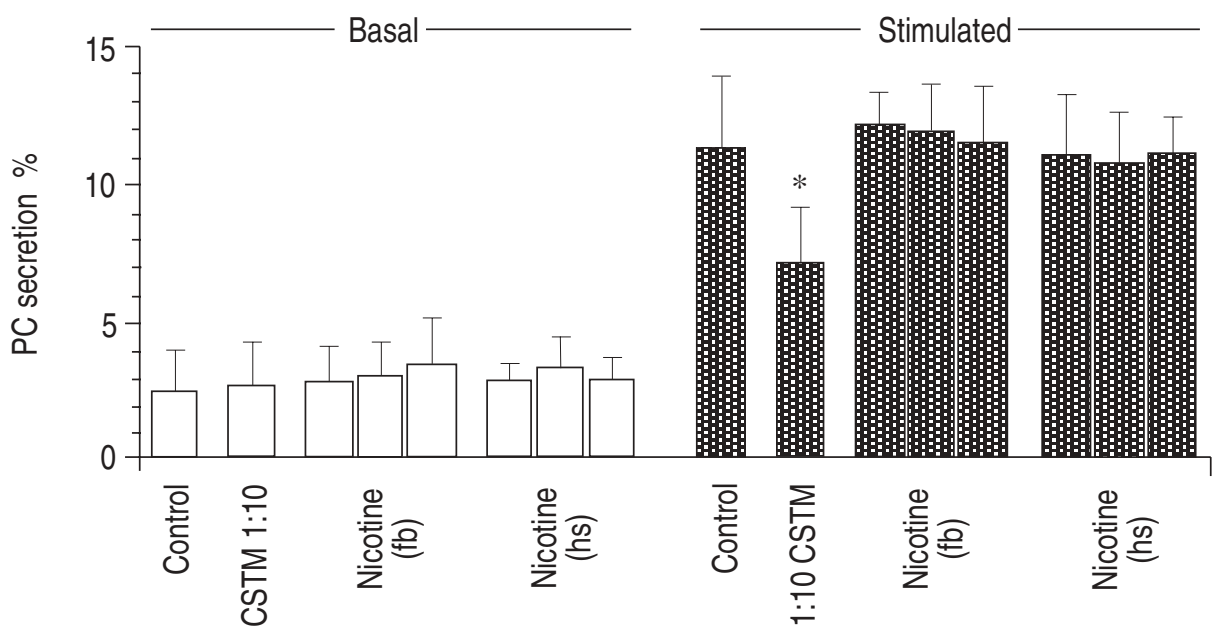

Fig. 6. - Influence of nicotine on T/T/A stimulated PC secretion (mean \pm SD) in type II cells. Nicotine was added to DMEM 30 min prior to and during the $2 \mathrm{~h}$ secretion period. 1:10 CSTM exposed cells served as positive controls. Concentrations of nicotine free base (fb) (from left to right): $10^{-7}, 10^{-6}$ and $10^{-5} \mathrm{M}(\mathrm{n}=4)$. Concentrations of nicotine hemisulphate salt (hs) (from left to right): $4 \times 10^{-8}, 4 \times 10^{-7}$ and $4 \times 10^{-6} \mathrm{M}(\mathrm{n}=4)$. *: significant difference of stimulated conditions vs stimulated controls. DMEM: Dulbecco's modified Eagle's medium. For further abbreviations see legend to figure 1.

Reduced glutathione (GSH) at concentrations of 50-1,000 $\mu \mathrm{M}$ (fig. $5 \mathrm{~b}$ ) as well as deferoxamine (Def) at a concentration of $0.5 \mathrm{mM}$ (fig. 5c), added as described for catalase and SOD, were also ineffective in restoring the normal secretory response to stimulation in type II cells. None of these antioxidants influenced basal or stimulated secretion in control cells. This was not true for $\alpha$ tocopherol, oxypurinol, mannitol and dimethylurea, which resulted in highly variable alterations of basal and stimulated secretion, so that interpretation of these results was not possible.

\section{Influence of nicotine and benzo[a]pyrene on PC secre- tion}

Cells were exposed to nicotine, to determine whether nicotine was responsible for inhibiting stimulated secretion of PC in type II cells. Increasing concentrations of the alkaloid were added to culture medium. Neither nicotine free base at a concentration of $10^{-7}, 10^{-6}$ and $10^{-5} \mathrm{M}$ nor the hemisulphate salt of nicotine at a concentration of $4 \times 10^{-8}, 4 \times 10^{-7}$ and $4 \times 10^{-6} \mathrm{M}$ were found to alter basal or T/T/A-stimulated PC secretion from type II cells (fig. 6).

The carcinogen benzo[a]pyrene, one of many polycyclic hydrocarbon ingredients in the "tar" fraction of cigarette smoke, acts as a protoxin which requires activation by the cell. It was dissolved in pure chloroform and added to DMEM, so that the final chloroform concentration to which cells were exposed, was $2.6 \times 10^{-5} \mathrm{M}$ for a benzo[a]pyrene concentration of $10^{-5} \mathrm{M}$ and, less for $10^{-6}, 10^{-7}$ and $10^{-8} \mathrm{M}$, respectively. Chloroform as a vehicle had no effect on basal or stimulated PC secretion in the highest concentration used (data not shown). Benzo[a]pyrene in concentrations ranging $10^{-8}-10^{-5} \mathrm{M}$ did not inhibit stimulated secretion (fig. 7) .

\section{Exposure of type II cells to CSTM at low temperature}

When cells were pre-exposed to 10 fold diluted CSTM at $4{ }^{\circ} \mathrm{C}$ instead of $37^{\circ} \mathrm{C}$, and then warmed up to $37^{\circ} \mathrm{C}$ for the secretion period, the secretory response to T/T/A agonists was no different from stimulated control cells exposed to DMEM at $37^{\circ} \mathrm{C}$ (fig. 8). However, cells exposed to 10 fold diluted $\mathrm{CSTM}$ at $37^{\circ} \mathrm{C}$ following the same protocol demonstrated a $52 \%$ reduction of stimulated secretion compared to control cells exposed to DMEM at

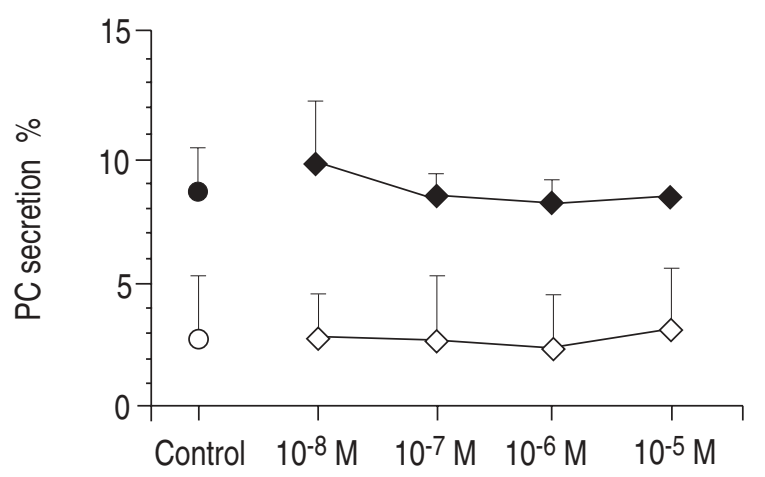

Fig. 7. - Influence of benzo[a]pyrene (dissolved in chloroform) on basal and stimulated PC secretion (mean \pm SD) in type II cells. Benzo[a]pyrene was added $30 \mathrm{~min}$ prior to and during secretion in the concentrations indicated. Open symbols: basal secretion; closed symbols: T/T/A stimulated secretion, $n=3$. For abbreviations see legend to figure 1 .

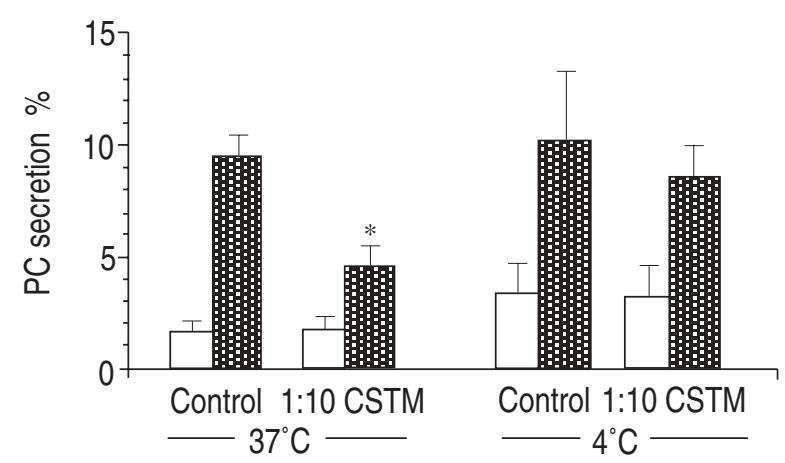

Fig. 8. - Influence of temperature $\left(37^{\circ}\right.$ vs $\left.4^{\circ} \mathrm{C}\right)$ during the exposure of type II cells to CSTM on basal and stimulated PC secretion (mean \pm SD). $\square$ : basal secretion; $\quad$ 明 : T/T/A stimulated secretion, $n=5$. *: significant difference of stimulated conditions $v s$ stimulated control at $37^{\circ} \mathrm{C}$. For abbreviations see legend to figure 1 . 
$37^{\circ} \mathrm{C}$, a $55 \%$ reduction compared to stimulated control cells exposed to DMEM at $4^{\circ} \mathrm{C}$ and a $46 \%$ reduction compared to cells exposed to 10 fold diluted CSTM at $4^{\circ} \mathrm{C}$. These findings demonstrate, that low temperature almost completely inhibited the CSTM induced reduction of T/T/A-stimulated PC secretion in type II cells. Both in control cells and 1:10 CSTM exposed cells at $4^{\circ} \mathrm{C}$ an increase of basal secretion was observed, which may have been induced by cooling and subsequent rewarming. However, this increase was not significant compared to basal secretion of either control or 1:10 CSTM exposed cells at $37^{\circ} \mathrm{C}$ (fig. 8).

\section{Discussion}

In this study, we report acute inhibition of phosphatidylcholine secretion in rat alveolar type II cells after exposure to medium treated with cigarette smoke. Whilst basal secretion remained unaffected, secretion stimulated by a combination of type II cell secretagogues (T/T/A) was inhibited by more than $50 \%$. Greater inhibition was observed with less diluted CSTM, i.e. a higher dose of cigarette smoke constituents retained in the medium. Longer exposure to CSTM resulted in greater inhibition. The reduced secretory response to agonists was not caused by cellular injury. Gas phase cigarette smoke was found to be much less inhibitory in this model. Although cigarette smoke contains large amounts of ROS, antioxidants in this study were not effective in abolishing the observed inhibition of stimulated secretion. Neither nicotine nor benzo[a]pyrene were able to mimic the described effects of CSTM on stimulated secretion. Exposure of cells to CSTM at low temperature $\left(4^{\circ} \mathrm{C}\right)$ resulted in a reconstituted response to secretagogues.

In contrast to the stimulatory effects of cigarette smoke on mucus secretion in whole animals [16] and in situ models [17], or the inhibitory effect of cigarette smoke on duodenal bicarbonate secretion [18], our model excludes influences by cells other than those examined, or by hormonal or neural activity.

A similar in vitro model was used to study cell injury, protein synthesis and cytokine production in alveolar macrophages [19]. In this study, the 1:15 diluted gas phase smoke of two cigarettes was blown over the cells cultured on a porous support. No cytotoxicity was observed and, whilst protein synthesis in general was unaffected, there was a reduced production of interleukin- 6 (IL-6) and tumour necrosis factor- $\alpha$ (TNF- $\alpha$ ) rather than decreased secretion 18-20 h following smoke exposure. Our results largely exclude decreased synthesis as a possible mechanism of decreased surfactant secretion by type II cells, because secretion involves the release of preformed lamellar bodies, the storage form of surfactant. The time between exposure and secretion period was too short to allow for a significant reduction of the preformed surfactant pool due to impaired synthesis. The lack of a difference of total counts and counts in the cellular fraction between cells exposed to CSTM and control cells also argues against impaired synthesis. It cannot be excluded, however, that incorporation of ${ }^{3} \mathrm{H}$-choline is preferentially routed into nonsurfactant phospholipids in CSTM exposed cells.

Although reduction of secretion stimulated by single agonists in this series of experiments did not exhibit significant differences, the possibility of impaired transmembrane signalling remains to be elucidated. It may involve common elements of different signalling pathways, such as $\mathrm{G}$ proteins, the cytoskeleton or membrane fusion. Some insight into the mechanism of CSTMinduced reduction of stimulated surfactant secretion is gained by the fact, that low temperature $\left(4^{\circ} \mathrm{C}\right)$ during exposure restores stimulated secretion to a normal level. Low temperature slows or abolishes metabolic processes and causes disruption of microtubules [20]. Active transport of smoke constituents into type II cells as well as their enzymatic metabolism would be impaired by low temperature, whilst a direct interaction with molecules of the cell membrane would not be inhibited.

Type II cells have been shown to express enzymes of the cytochrome P-450 monoxygenase system, which are involved in xenobiotic metabolism [21-24]. For example, bioactivation of the cigarette smoke ingredient 3methylindole by rabbit type II cells in culture has been demonstrated [25]. Benzo[a]pyrene, contained in the particulate phase of cigarette smoke is reported to be activated in Clara cells and type II cells. The smoke of one cigarette contains approximately $30 \mu \mathrm{g}$ of benzo[a]pyrene [26]. A maximum concentration of $2.5 \times 10^{-7} \mathrm{M}$ is calculated for the smoke of four cigarettes at a $50 \%$ absorption rate in $100 \mathrm{~mL}$ DMEM, diluted 10 fold. Benzo[a]pyrene at this and higher concentrations failed to mimic the influence of CSTM on stimulated surfactant secretion in this study.

Nicotine, another component of the particulate phase of cigarette smoke, may reach type II cells from the airspace as well as from the capillary side. 1R1 cigarettes are reported to contain $2 \mathrm{mg}$ of nicotine [27]. Assuming that $50 \%$ of $8 \mathrm{mg}$ (for four cigarettes) is absorbed by the $100 \mathrm{~mL}$ DMEM along the $5 \mathrm{~cm}$ distance between bubble outlet and surface of the medium, which is followed by a minimum 10 fold dilution, $4 \mathrm{mg} \cdot \mathrm{L}^{-1}$ (approximately $\left.2.5 \times 10^{-5} \mathrm{M}\right)$ is probably still an overestimation. The highest concentration of nicotine (free base) used in this study was $1 \times 10^{-5} \mathrm{M}$ and, thus, equivalent to the concentration in 1:25 diluted CSTM. 1:25 diluted CSTM in our experiments resulted in a $45 \%$ reduction of stimulated secretion $(\mathrm{p}<0.05$; fig. 4$)$, whilst no decrease in stimulated secretion was seen with $1 \times 10^{-5} \mathrm{M}$ nicotine (fig. 6).

The inefficiency of antioxidants to restore the reduced secretory response of stimulated type II cells exposed to CSTM was unexpected. Cigarette smoke contains a large number of ROS [28], and part of the smoking-induced lung injury can be attributed to this oxidizing capacity [29]. The scavengers used in this study have been used effectively in other models of oxidant injury. Catalase and superoxide dismutase, both cell impermeable, as well as the iron chelator deferoxamine inhibited the cigarette smoke-induced increase in asbestos fibre uptake in rat tracheal explants when added to the incubation medium in concentrations lower than the maximum concentrations used in this study [30]. Deferoxamine was shown 
to prevent paraquat-induced injury to type II cells [15]. In an in vitro model using A549 cells exposed to hydrogen peroxide $(15 \mu \mathrm{M})$, GSH greatly diminished detachment and lysis in a dose dependent manner [31]. GSH concentration in normal human epithelial lining fluid (ELF) is $430 \mu \mathrm{M}$ [32]. The highest GSH concentration used here exceeded this concentration more than twofold. The failure of antioxidants to show any effect on the reduction of stimulated surfactant secretion may, nevertheless, be due to their inability to neutralize a sufficient amount of ROS. Alternatively, the reduction of stimulated surfactant secretion is not mediated by ROS. The later hypothesis is supported by the reduced ability of medium treated with gas phase cigarette smoke to inhibit stimulated surfactant secretion, since large amounts of ROS have been described in both the particulate as well as the gas phase of cigarette smoke [33]. In addition, mediation of reduced stimulated surfactant secretion by ROS would also contradict results of experiments at low temperature, where oxidant damage is still possible.

The smoke exposure model described here is easy to use; however, it appears realistic. Our photometric standardization to a reference value, which depends on a summary signal, does not exclude variation of virtually all cigarette smoke ingredients to some extent, but did result in a highly reproducible biological response. When cigarette smoke, a complex mixture of hydrophilic and hydrophobic components, is bubbled through cell culture medium, it will not result in a homogenous solution with all ingredients in proportions similar to cigarette smoke. Hydrophilic compounds will undoubtedly be retained preferentially. This phenomenon, however, is not unlike the environment in the alveolus, where a liquid lining covers the epithelium.

The concentration of cigarette smoke ingredients used for treating the medium should not exceed that estimated to occur during smoking in lung ELF: the fraction of cigarette smoke that is retained in the lung will be distributed in an estimated volume of $10 \mathrm{~mL}$ of ELF. The distribution volume for the retained fraction of the smoke of four cigarettes here is $100 \mathrm{~mL}$. In addition, medium is further diluted 10-100 fold, increasing the distribution volume to 1-10 L. Because of the large surface area in the lung, a greater proportion of smoke will be retained in the lung than can be achieved by bubbling the smoke over a distance of $5 \mathrm{~cm}$ through medium.

Duration of the inhibition of stimulated surfactant secretion, which may be important considering the pathogenetic impact, appears to be at least $3 \mathrm{~h}$, as is suggested by experiments examining the influence of exposure time on secretion. Following stimuli, such as mechanical distension or humoral agonists $11-40 \%$ of the alveolar pool of surfactant is secreted and cleared per hour [34, 35]; and impairment of surfactant secretion for several hours will be significant and may represent an insufficiently recognized part of the pathogenesis of smoke-related lung disease.

Our findings, demonstrating inhibition of stimulated secretion of surfactant following cigarette smoke exposure, correlate with results of whole animal studies, demonstrating unimpaired incorporation of surfactant precursors [5], as well as with clinical reports showing decreased surfactant phospholipids in the lavage fluid of smokers [1-3]. This is the first report, however, linking cigarette smoke exposure directly to impaired surfactant secretion from type II cells.

In summary, we have shown a direct acute influence of cigarette smoke on stimulated surfactant secretion without alteration of basal secretion. The particulate fraction of cigarette smoke was more effective than the gas phase. The exact mechanism remains to be elucidated. However, our experiments suggest that oxidant injury is not prominent and that a metabolic process, such as bioactivation or active transport, which is inhibited by low temperature, is involved in the smoke-induced reduction of stimulated surfactant secretion.

Acknowledgements: Expert technical assistance was provided by $\mathrm{C}$. Omert.

\section{References}

1. Finley TN, Ladman AJ. Low yield of pulmonary surfactant in cigarette smokers. N Engl J Med 1972; 286: 223-227.

2. Lusuardi M, Capelli A, Carli S, Tacconi MT, Salmona M, Donner CF. Role of surfactant in chronic obstructive pulmonary disease: therapeutic implications. Respiration 1992; 59: 28-32.

3. Würtemberger G, Herceg R, Matthys H, Ferber E, Costabel U. Surfactant-Phospholipide der BAL-Flüssigkeit bei lungengesunden Rauchern und Nichtrauchern. Pneumologie 1990; 44: 310-311.

4. Clements JA. Smoking and pulmonary surfactant. $N$ Engl J Med 1972; 286: 261-262.

5. Giammona ST, Tocci P, Webb WR. Effects of cigarette smoke on incorporation of radioisotopically labeled palmitic acid into pulmonary surfactant and on surface activity of canine lung extracts. Am Rev Respir Dis 1971; 104: 358-367.

6. Barlow Y, Lamb D. The effect of cigarette smoking on cell number and cell proliferation in the alveolar walls of man. Thorax 1985; 40: 214-215.

7. DeBardeleben MZ. In: Dictionary of tobacco terminology. Richmond, Virginia, Philipp Morris Research Center, 1980; p. 12.

8. Dobbs LG, Gonzalez RF, Williams MC. An improved method for isolating type II cells in high yield and purity. Am Rev Respir Dis 1986; 134: 141-145.

9. Dobbs LG, Wirtz HRW, Pian MS. Regulation of surfactant secretion in cultured type II cells. In: Mueller B, von Wichert P, eds. Basic Research on Lung Surfactant. Progress in Respiratory Research. Basel, Karger, 1990; 25: 115-121.

10. Kikkawa Y, Yoneda K. The type II epithelial cell of the lung. I. Method of isolation. Lab Invest 1974; 30: 76-84.

11. Folch J, Lees M, Stanley GHS. A simple method for the isolation and purification of total lipids from animal tissues. J Biol Chem 1957; 226: 497-509.

12. Dobbs LG, Mason RJ. Stimulation of secretion of desaturated phosphatidylcholine from isolated alveolar type II cells by 12-O-tetradecanoyl-13-phorbol acetate. Am Rev Respir Dis 1978; 118: 705-713. 
13. Wirtz HRW, Dobbs LG. Calcium mobilization and exocytosis after one mechanical stretch of lung epithelial cells. Science 1990; 250: 1266-1269.

14. Fanestil DD, Barrows CH. Aging in the rotifer. $J$ Gerontol 1965; 20: 462-469.

15. van der Wal NAA, van Oirschot JFLM, van Dijk A, Verhoef J, van Asbeck BS. Mechanism of protection of alveolar type II cells against paraquat-induced cytotoxicity by deferoxamine. Biochem Pharmacol 1990; 39: 1665-1671.

16. Coles SJ, Levine L, Reid L. Hypersecretion of mucus glycoproteins in rat airways induced by tobacco smoke. Am J Pathol 1979; 94: 459-472.

17. Rogers DF, Turner NC, Mariott C, Jeffrey PK. Cigarette smoke-induced "chronic bronchitis": an in situ study of laryngotracheal hypersecretion in the rat. Clin Sci 1987; 72: 629-637.

18. Granstam S-O, Jönson C, Fändriks L, Holm L, Flemström G. Effects of cigarette smoke and nicotine on duodenal bicarbonate secretion in the rabbit and the rat. J Clin Gastroenterol 1990; 12 (Suppl. 1): S19-24.

19. Dubar V, Gosset P, Aerts C, Voisin C, Wallaert B, Tonnel $\mathrm{AB}$. In vitro acute effects of tobacco smoke on tumor necrosis factor- $\alpha$ and interleukin-6 production of alveolar macrophages. Exp Lung Res 1993; 19: 345-359.

20. Tilney LG. Origin and continuity of microtubules. In: Reinert J, Ursprung H, eds. Origin and continuity of cell organelles. New York, Springer Verlag, 1971.

21. Devereux TR. Alveolar type II and Clara cells: isolation and xenobiotic metabolism. Environ Health Persp 1984; 56: 95-101.

22. Devereux TR, Anderson MW, Belinsky SA. Factors regulating activation and DNA alkylation by 4-(N-methylN-nitrosamino)-1-(3-pyridl)-1-butanone and nitrosdimethylamine in rat lung and isolated lung cells, and the relationship to carcinogenicity. Cancer Res 1988; 48: 4215-4221.

23. Plopper CG, Dungworth DL. Structure, function, cell injury and cell renewal of bronchiolar and alveolar epithelium. In: McDowell EM ed. Lung carcinoma. London, Churchill Livingstone, 1987; pp. 29-44.
24. Serabijt-Singh CJ, Nishio SJ, Philpot RM, Plopper CG. The distribution of cytochrome P-450 monooxygenase in cells of the rabbit lung: an ultrastructural immunocytochemical characterization. Mol Pharmacol 1988; 33: 279-289.

25. Nichols WK, Larson DN, Yost GS. Bioactivation of 3methylindole by isolated rabbit lung cells. Toxicol and Appl Pharmacol 1990; 105: 264-270.

26. Smoking and Health. A report of the Surgeon General. DHEW Publication No. (PHS) 79-50066, 1979; 14: 54.

27. Benner JF. Tentative summary of leaf and smoke analysis of the university of Kentucky reference and alkaloid series cigarettes. Conference Proceedings of Tobacco and Health Conference, Lexington, Kentucky, 1970. University of Kentucky, Tobacco and Health Research Institute, pp. 30-34.

28. Church T, Pryor WA. Free radical chemistry of cigarette smoke and its toxicological implications. Environ Health Perspect 1985; 64: 111-126.

29. Idell S, Garcia JGN. Mechanisms of smoking-induced lung injury. Semin Respir Med 1989; 10: 345-355.

30. Churg A, Hobson J, Berean K, Wright J. Scavengers of active oxygen species prevent cigarette smoke-induced asbestos fibre penetration in rat tracheal explants. Am J Pathol 1989; 135: 599-603.

31. MacNee W, Bridgeman MME, Marsden M, et al. The effects of $\mathrm{N}$-acetylcysteine and glutathione on smokeinduced changes in lung phagocytes and epithelial cells. Am J Med 1991; 91 (Suppl. 3C): 60-66S.

32. Cantin AM, North SL, Hubbard RC, Crystal RG. Normal alveolar epithelial lining fluid contains high levels of glutathione. J Appl Physiol 1987; 163: 152.

33. Pryor WA, Prier DG, Church DF. Electron-spin resonance study of mainstream and sidestream smoke: nature of the free radicals in gas-phase smoke and in cigarette tar. Environ Health Perspect 1983; 47: 345-355.

34. Wright JR, Clements JA. Metabolism and turnover of lung surfactant. Am Rev Respir Dis 1987; 135: 426-444.

35. Wirtz H, Schmidt M. Ventilation and secretion of pulmonary surfactant. Clin Invest 1992; 70: 3-13. 